\title{
Benchmarking economic infrastructure efficiency: How does the Latin America and Caribbean region compare?
}

\author{
Ancor Suárez-Alemán ${ }^{\mathrm{a}, *}$, Tomás Serebrisky ${ }^{\mathrm{a}}$, Sergio Perelman ${ }^{\mathrm{b}}$ \\ a Inter-American Development Bank, USA \\ ${ }^{\mathrm{b}}$ HEC University de Liège, Belgium
}

\section{A R T I C L E I N F O}

\section{Keywords:}

Infrastructure

Efficiency

Latin America and the CaribbeanJEL

classification:

H54

018

R53

\begin{abstract}
A B S T R A C T
The Latin America and Caribbean (LAC) region has a sizable infrastructure gap. Physical assets, maintenance, and service provision are inadequate and below average for a region at its level of development. The most promising way to close the service gap is to increase efficiency. Relying on data on more than 80 countries for 2000 and 2016, this paper innovates by 1) developing a single economic infrastructure index to compare countries; 2) presenting an efficiency analysis that assesses whether LAC countries have room for improvement in the provision of the quantity and quality of economic infrastructure; 3) proposing a novel peer-identification conceptual framework to identify which countries are the relevant benchmarks for the region; and 4) providing evidence on how sound governance, regulation, rule of law, and the lack of corruption are related to infrastructure efficiency at the country level.
\end{abstract}

\section{Introduction}

The Latin America and Caribbean (LAC) region has a sizable infrastructure gap. ${ }^{1}$ Multiple studies conclude that the region needs to invest at least 5 percent of GDP in infrastructure over a prolonged period to close this gap (Bhattacharya et al., 2012; Calderón and Servén, 2003; Perrotti and Sánchez, 2011). LAC countries have invested an average of 3.5 percent of their annual GDP in infrastructure since 2008 (see Fig. 1). If the estimates are correct, LAC requires additional infrastructure investment of 2.0-2.5 percent of GDP or $\$ 120$ to $\$ 150$ billion a year (based on 2013 GDP figures).

According to the World Economic Forum's survey (WEF, 2018) of perceptions of infrastructure quality, the quality of infrastructure in LAC lags that of advanced economies and fast-growing Asian economies. Even worse, the quality gap with Sub-Saharan Africa is shrinking: Africa's quality indicators may soon match or even surpass those of LAC (Serebrisky et al., 2015). Lack of physical assets, inadequate maintenance, and poor provision of infrastructure services explain the perception that infrastructure services in the region are of low quality (Serebrisky et al., 2017).

Infrastructure in the region is less developed than it should be given the region's income level, adversely affecting the quality of life and competitiveness. Investment is insufficient, and the quality of services is low (Cerra et al., 2016). Most countries in the region score lower on infrastructure quality than expected given their level of per capita income. $^{2}$ The International Monetary Fund (IMF) developed countryspecific benchmarks for the region's six largest economies (Argentina, Brazil, Chile, Colombia, Mexico, and Peru) by identifying the top five competitors for each of the top five export products in each country. The results show that Chile is the only country in LAC-6 with infrastructure that can compete with that of its trading rivals. And even in Chile, the competitiveness of its exports declined between 2008 and 2015 (IMF, 2016).

A simple way forward for the LAC region to close its infrastructure gap would be to invest more. However, in the last several decades, infrastructure investment has not increased to the level compatible with closing the gap. LAC has tried to overcome low levels of public investment in infrastructure fostering private investment. Ongoing policy reforms since the mid-1990s increased private sector investment from a negligible amount to one percent of GDP by 2015 . Despite the increase, private investment has not constituted the "game changer" and the public sector still accounts for more than two-thirds of total investment

\footnotetext{
* Corresponding author. Inter-American Development Bank, 1300 New York Ave NW, 20577, Washington DC, USA.

E-mail addresses: ancorsuarez@gmail.com, ancors@iadb.org (A. Suárez-Alemán).

${ }^{1}$ The most common approach to measuring the infrastructure gap is in terms of needs with respect to meeting a target economic growth rate, achieving a specific objective such as a coverage rate, or achieving an infrastructure stock similar to that of another country or group of countries (Serebrisky et al., 2015).

${ }^{2}$ The quality of infrastructure in Argentina, Bolivia, Brazil, Paraguay, and Venezuela is considerably lower than expected given their income levels. Guatemala, Panama, and El Salvador have better-than-expected infrastructure quality, according to the World Economic Forum (2016).
} 


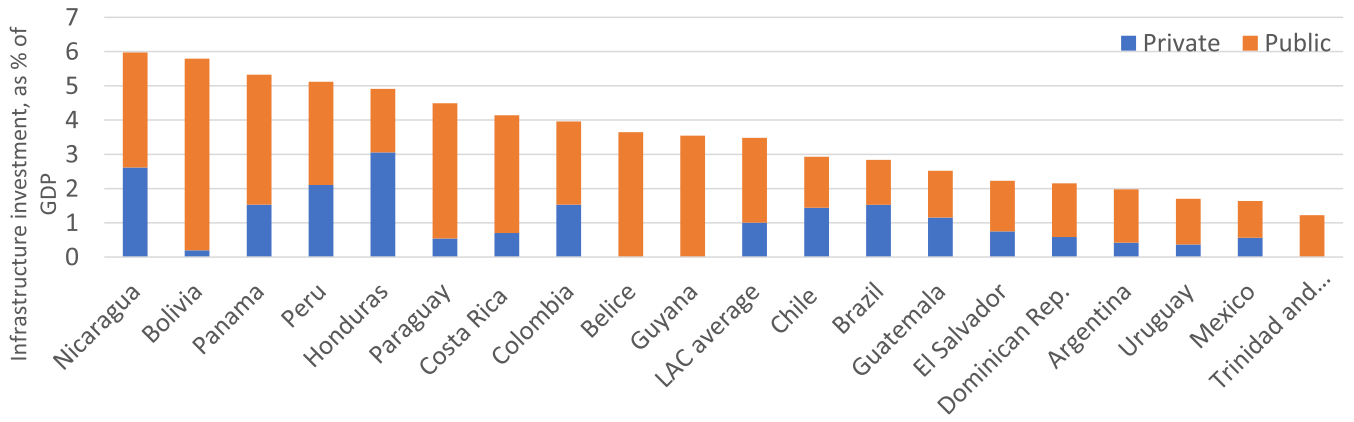

Fig. 1. Average investment in infrastructure as a percentage of GDP in LAC, by country, 2008-15.

Source: www.infralatam.info.

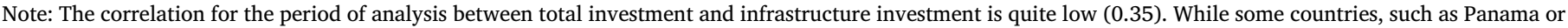

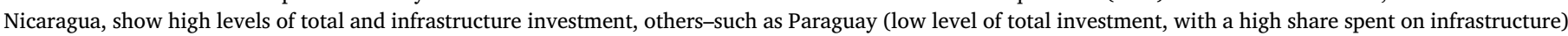

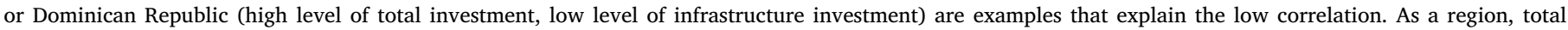
investment in Latin American was, on average, 22 percent of GDP in the period of analysis, while infrastructure investment reached 3.5 percent of GDP.

in the region (Serebrisky et al., 2017).

The evolution of public investment in LAC indicates that relying on public funding for infrastructure investment can be risky in times of fiscal imbalance. Within LAC, allocations to public infrastructure investment have been cut in times of deteriorating fiscal balances. ${ }^{3}$ Moreover, the LAC region is characterized by a bias against capital expenditures in favor of current expenditures. A clear indication of this bias is provided by what happened during the commodities boom in LAC, a period where one would expect to see a strong increase in capital expenditures. In fact, from 2007 to 2014, public expenditure in LAC increased 3.8 percent of GDP but capital expenditure only explained 8 percent of that increase (Cavallo and Serebrisky, 2016).

For every country, the efficiency of infrastructure investment should be a policy priority, yet this is even more important for LAC. Given the low level of fiscal space traditionally allocated to infrastructure, the fact that public investments in infrastructure are highly dependent on the economic cycle, as well as the insufficient level of private investment, the most promising way to close the quantitative and qualitative infrastructure gap in LAC is to increase efficiency.

What do we know about the efficiency of infrastructure provision in LAC? An emergent strand of empirical studies attempts to measure the efficiency of infrastructure in LAC, producing sector-specific analyses, and mainly focused on ports, airports, electricity distribution, water, and sanitation. In the Appendix, Table A1. comprises a sample of recent studies on sector-based efficiency analysis. The evidence shows that the efficiency of service provision in LAC has ample room for improvement.

No study has heretofore addressed the efficiency of infrastructure as a whole in the region. The present paper fills that gap. The ultimate objective is to measure the efficiency by which a country translates its capital stock (the accumulated history of investment) into an indicator that reflects the endowment and quality of its infrastructure. The paper first describes the infrastructure endowment, quality, and capital stock in the region and compares it with other countries to understand where the region stands today and historically. This paper then investigates

\footnotetext{
${ }^{3}$ Carranza et al. (2014) argue that between 1987 and 1992, a period of financial and fiscal crisis in LAC, " one-third of the improvement in fiscal accounts can be effectively attributed to lower infrastructure investment." Public deficits were reduced to 6 percent of GDP, and public investments in infrastructure diminished to 2 percent of GDP on average, the equivalent of a reduction of more than 60 percent of public infrastructure investment (Serebrisky et al., 2015). Total expenditures in LAC increased by 3.7 percent of GDP between 2007 and 2014, but more than 90 percent of the increase went to current expenditures; only 8 percent was devoted to longer-term investments (Cavallo and Serebrisky, 2016).
}

whether there is room for efficiency improvements and whether such improvements could help close the infrastructure gap in LAC. Frontier analysis is used to measure how efficiently resources are employed to develop infrastructure services. Resources are represented by countries' efforts in the development of infrastructure (proxied by the capital stock to GDP ratio), and infrastructure services are measured by a set of indicators, mainly access to services, weighted by quality.

\section{How does Latin America and the Caribbean compare with other regions? developing a single indicator for benchmarking economic infrastructure}

The analysis of infrastructure quality and endowment is usually carried out at the sector level. This is explained by sector specificities. The World Economic Forum's survey on perceptions of infrastructure reveals that the quality of infrastructure in LAC is lagging, particularly compared with the developed world (Serebrisky et al., 2017). When it comes to infrastructure endowment, despite low levels of investment, access to infrastructure services improved greatly in LAC between 2000 and 2015. The region still lags the developed world, however, although access levels are higher than in South Asia and Africa. LAC faces the "last-mile connection" problem: universal access to electricity, water, and sanitation has still not been achieved. Access has been a policy priority in the electricity and water sectors although rural areas lag behind. On a country-by-country analysis, we find these access problems are concentrated in a few countries. Moreover, access to the Internet remains a challenge and requires targeted and continuous policy action to make discrete progress towards universal coverage. Regarding transport, the share of the paved road network in LAC experienced almost no change over the last two decades. ${ }^{5}$

\footnotetext{
${ }^{4}$ While WEF's quality of infrastructure indicator has been criticized-as their results may not be perfectly comparable among economies and the concept of overall infrastructure may be hard to conceptualize by respondents-it constitutes the only source of information for quality assessment in the infrastructure sector worldwide. Future research should explore tailor-made indicators for every sector and subsector.

${ }^{5}$ The transport sector reveals the complexity involved in selecting representative indicators. In the case of roads, this problem is acute. The share of paved roads is weakly correlated with other transport indicators, including the number of containers moved ( $r=0.32)$, kilometers of rail lines $(r=0.37)$, and the number of air transport passengers $(r=0.40)$. Other subsectors may be more affected by third-party or indirect users, such as transshipment traffic when it comes to maritime transport, or international passengers in an international hub when it comes to air transport. Following this reasoning, the state
} 
Developing a single indicator that captures the state of infrastructure is difficult because it has to consider not only the access dimension of infrastructure (after all, access is the necessary condition to satisfy the demand for a given service) but also its quality (how users value the services provided). The motivation to have a single indicator that aggregates all economic infrastructure sectors is the possibility of producing cross-country and time-series comparisons that cater to audiences outside the infrastructure sector, such as ministries of finance, who tend to be responsible for allocating public resources to fund infrastructure.

The present paper develops a single indicator for infrastructure services that captures both access (or it can even be interpreted as capturing availability) and quality of services. It is possible to reduce the number of variables while retaining much of the information in the original data, using principal component analysis (PCA) (Jolliffe and Cadima, 2016). PCA is a multivariate technique that uses an orthogonal transformation to convert a set of observations of possibly correlated variables into a set of values of linearly uncorrelated variables called principal components (Abdi and Williams, 2010). This approach allows researchers to identify patterns in data: once these patterns are found, the data can be compressed by reducing the number dimensions without significant loss of information (Andres, 2007).

Through PCA, the information contained in the variables on access to economic infrastructure (electricity, water and sanitation, and the Internet) together with two other supply-oriented variables (electricity generation and the paved road network) are summarized in a single indicator. ${ }^{6}$ All of these variables are weighted by the users' perception of infrastructure quality from the WEF data. This infrastructure index accounts for almost 90 percent of the information (see Appendix Table A. 3 for estimation results and scores by country). ${ }^{7}$ Fig. 2 displays the results of the PCA calculations for 2000 and 2016.

A glance at the infrastructure indicator provides a clear conclusion: LAC is far from the developed world; only South Asia and Sub-Saharan African countries perform worse. Performance improved slightly between 2000 and 2016, but LAC countries remain far from the top and lost some of their advantage relative to South Asian and Sub-Saharan African countries.

It is reasonable to expect that increasing investment in infrastructure should have a positive impact on the indicator as it is likely that both access and quality increase. However, the correlation is far from one. Data on the total capital stock (the sum of historical investment), which is a proxy for infrastructure stock, ${ }^{8}$ reveal huge

\section{(footnote continued)}

of roads in a country such as Sri Lanka or Panama would be more representative of transport infrastructure services in the country than the number of cargo containers or air transport passengers moved. The share of paved roads is highly correlated with other infrastructure indicators (energy, water, sanitation, and telecommunications), possibly implying that it represents a more appropriate proxy for the overall state of infrastructure services in a country.

${ }^{6}$ Data on electricity generation are from the OECD Dataset on World Energy Balances.

${ }^{7}$ The first PCA component, which explains 90 percent of total variance, is highly correlated with quantity-quality variables, e.g., in 2000: sanitation (0.98), electricity (0.96), water (0.96), telecommunications (0.96), transport (0.86), and electricity generation (0.52).

${ }^{8}$ The total capital stock variable was developed by the IMF (2015). The authors constructed the capital stock indicator from data on general investment (gross fixed capital formation). According to the World Bank, Gross fixed capital formation (formerly gross domestic fixed investment) includes land improvements (fences, ditches, drains, and so on); plant, machinery, and equipment purchases; and roads, railways, schools, offices, hospitals, private residential dwellings, and commercial and industrial buildings. According to the 1993 SNA, net acquisitions of valuables are also considered capital formation. Using a stock dimension avoids the usual huge variations observed in investment. The IMF inventory-based methodology makes it possible to calculate a capital stock variable by considering historical investment and accounting for depreciation. This variable differences across regions (Fig. 3, Panel a) when measured on a per capita basis. These differences narrow once the size of regional economies is accounted for (Fig. 3, Panel b). This finding is consistent with growth accounting exercises that show that the amount of physical capital accumulation (as a share of GDP) in LAC was similar to other regions in GDP relative terms (Cavallo and Powell, 2018).

Countries in different regions allocate similar shares of their resources to their capital stocks, but the assets developed and the quality of services produced by these assets are much lower in LAC than in other regions. Cavallo and Powell (2018) show that overall investment efficiency, defined as the ratio of GDP growth (net of the contribution of raw labor and skills) to the net investment rate, is lower in LAC than in the rest of the world. ${ }^{9}$

The working hypothesis of this paper (confirmed by the data) is that LAC underperforms when it comes to infrastructure efficiency: The region is not making the most of the resources allocated to produce infrastructure services. To test this hypothesis, the next section develops an efficiency frontier using DEA methodology on a sample of 81 countries.

\section{Frontier analysis of economic infrastructure efficiency}

\subsection{Data Envelopment Analysis (DEA)}

DEA is a nonparametric, deterministic method that uses mathematical programming techniques to envelop the data as compactly as possible with the aim of building a piece-wise linear frontier. DEA differs from a simple efficiency ratio in that it accommodates multiple inputs and outputs and provides significant additional information about where efficiency improvements can be achieved and the magnitude of these potential improvements (Sherman and Zhu, 2006). It does so without the need to know the relative values (prices) of the outputs and inputs, which are needed for the computation of productivity indexes.

This methodology may cover a range of singularities regarding the final model setting, mainly the model orientation and returns to scale. When it comes to model orientation, an input-oriented model implies that efficiency analysis is concerned with minimizing inputs to produce a specific level of output; in an output-oriented model, the objective is to maximize the proportional increase in output while remaining within the production possibility set. Regarding returns to scale, the constant returns to scale model (DEA-CCR, CRS) allows for comparison among units of different size, such that all observed production combinations can be scaled up or down proportionally. The variable returns to scale model (DEA-BCC, VRS) allows for the determination of scale efficiency as the distance between both variable and constant returns to scale frontiers. ${ }^{10}$ Fig. 4 shows how DEA works in a one-input, one-output scenario. Two frontiers can be estimated, one assuming constant returns to scale and another assuming variable returns to scale.

\section{(footnote continued)}

comprises much more than economic infrastructure (investments in energy, telecommunications, transport, water, and sanitation). However, there is no historical and comparable information on investment in infrastructure for a large sample of countries worldwide. There is a strong need to develop stock accounting exercises for infrastructure. However, Appendix Table A.2 shows that the average investment in infrastructure represents about 15 percent of total gross fixed capital formation. Appendix Fig. A1 shows how stable this share has been over time. Therefore, for estimation/calculation purposes, the capital stock may constitute a suitable proxy for the infrastructure stock.

${ }^{9}$ Cavallo and Powell find that a one percentage point increase in investment as a share of GDP increases GDP by about 0.28 percentage points in emerging Asia and by only about 0.20 percentage points in LAC.

${ }^{10}$ In their seminal work, Charnes et al. (1978) assumed constant return to scale, that is, all observed combinations can be scaled up or down proportionally (the DEA-CCR model). Later work (Banker et al., 1984) allowed for variable returns to scale (the DEA-BCC model). 


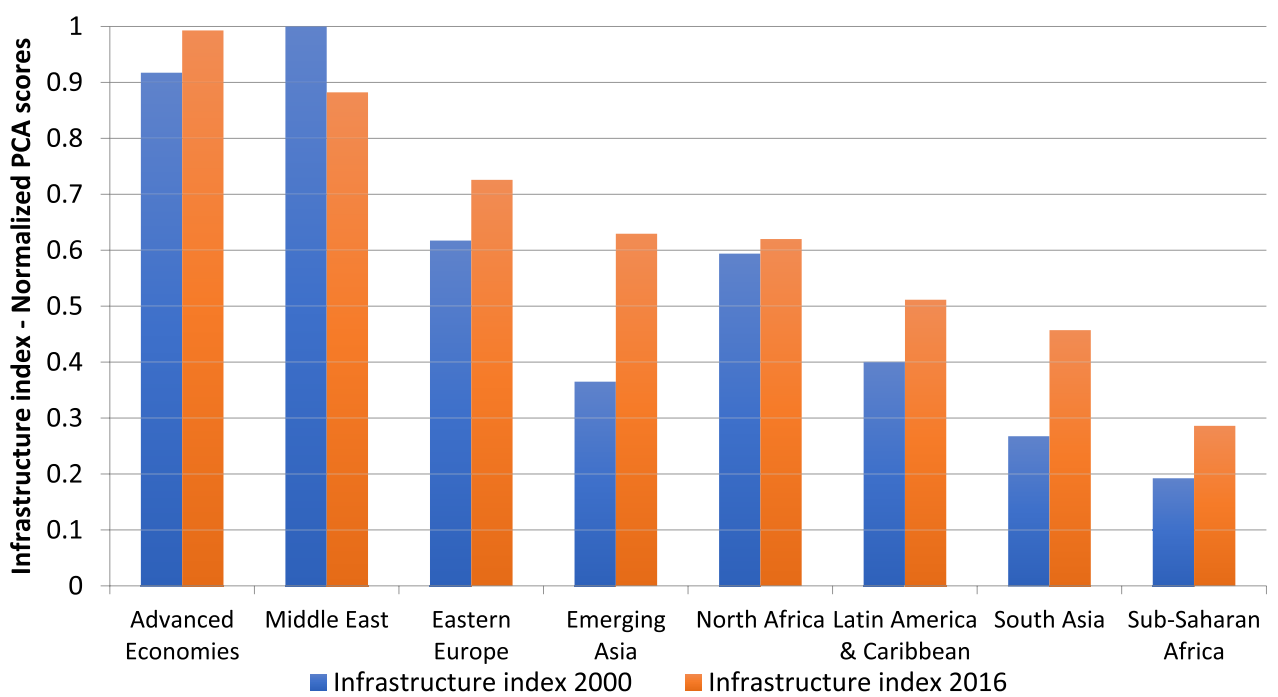

Fig. 2. Infrastructure index by region, 2000 and 2016.

Source: Data from World Bank (2018) and CIA World Factbook.

Note: Infrastructure index shows normalized scores based on PCA results.

a. Per million people

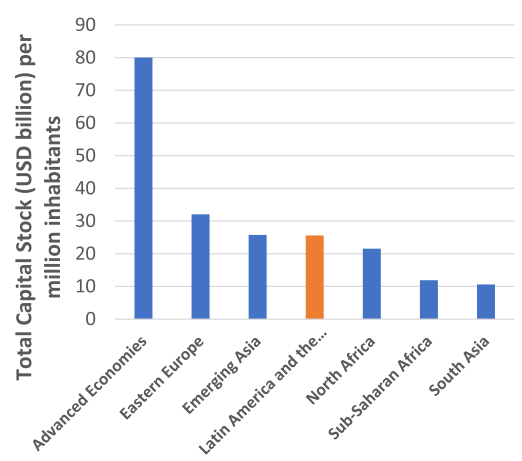

Fig. 3. Total capital stock by region, 2016

Source: Data from the IMF.

The points A, B, C, D, and E in Fig. $\mathrm{X}$ illustrate the observed quantities of input used and output produced by different countries. A is the only point at which a country is efficient under both constant and variable returns to scale. $B$ and $C$ are efficient under variable returns to scale, with $B$ in the region of increasing returns to scale and $C$ in the region of decreasing returns to scale. $\mathrm{D}$ and $\mathrm{E}$ are inefficient. They could produce more output with the same input quantity. Country E uses quantity $\mathrm{R}$ of input $\mathrm{x}$ to produce quantity $\mathrm{RE}$ of output $\mathrm{y}$ (HerreraDappe and Suárez-Alemán, 2016).

The vector $\mathrm{EE}_{\mathrm{C}}$ measures the distance to the best practice frontier. It can be decomposed into two parts. $\mathrm{EE}_{\mathrm{V}}$ corresponds to pure inefficiency; $E_{V} E_{C}$ denotes inefficiency caused by the scale of operation (scale inefficiency). Countries A and C form the piecewise linear combination benchmark with which port $\mathrm{E}$ is compared. The peers for countries D are B and A. Under constant returns to scale, country A is the benchmark for all the other countries (Herrera-Dappe and SuárezAlemán, 2016). For a detailed explanation of the DEA mathematical specification see Coelli et al. (2005).

\subsection{The efficiency frontier}

We develop a production function in which total capital stock (relative to GDP) is used to produce infrastructure services. We use the variable capital stock/GDP to account for varying availability of b. Per GDP

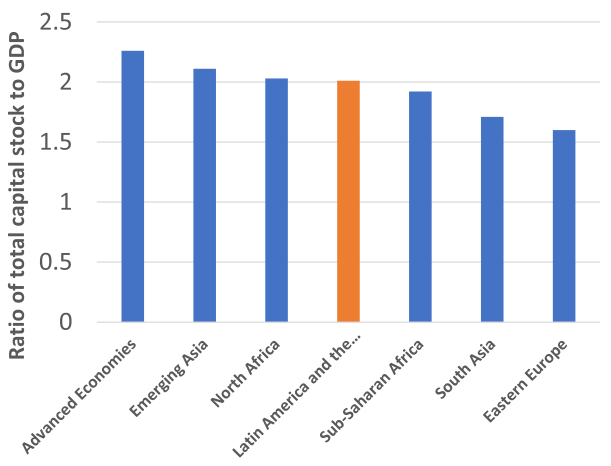

resources to produce given outputs. By relativizing to GDP, we account for the relative effort of each country and the higher/lower relative costs of developing infrastructure in richer/poorer countries. We rely on Herrera and Pang (2005), who proceed in this way in a study on efficiency in public spending in education across the world (140 countries). In their study, public spending in education is deflated by GDP considering that relative prices and wages are driven by the marginal productivity of labor at the country level. Also, they argue that the elasticity of demand for publicly provided services increases with economic development, as postulated by Wagner's Law on Increasing State Spending. The exercise was also implemented with an alternative measure of capital stock that corresponding to public sector investments exclusively, computed by the IMF (2015) as well. Efficiency frontier results from total capital stock (reported in this paper) and just the public capital stock are highly correlated $(0.96) .^{11}$

Infrastructure endowment variables include access to the Internet; access to improved water, electricity, and sanitation; electricity

\footnotetext{
${ }^{11}$ If the assumption that the total share is stable over time is accepted as valid (see footnote 8 for justification), the different endowment of infrastructure stock among countries is picked up by the DEA (there is a difference in magnitude, but the relative comparison across economies is similar when we account for total stock or infrastructure stock).
} 


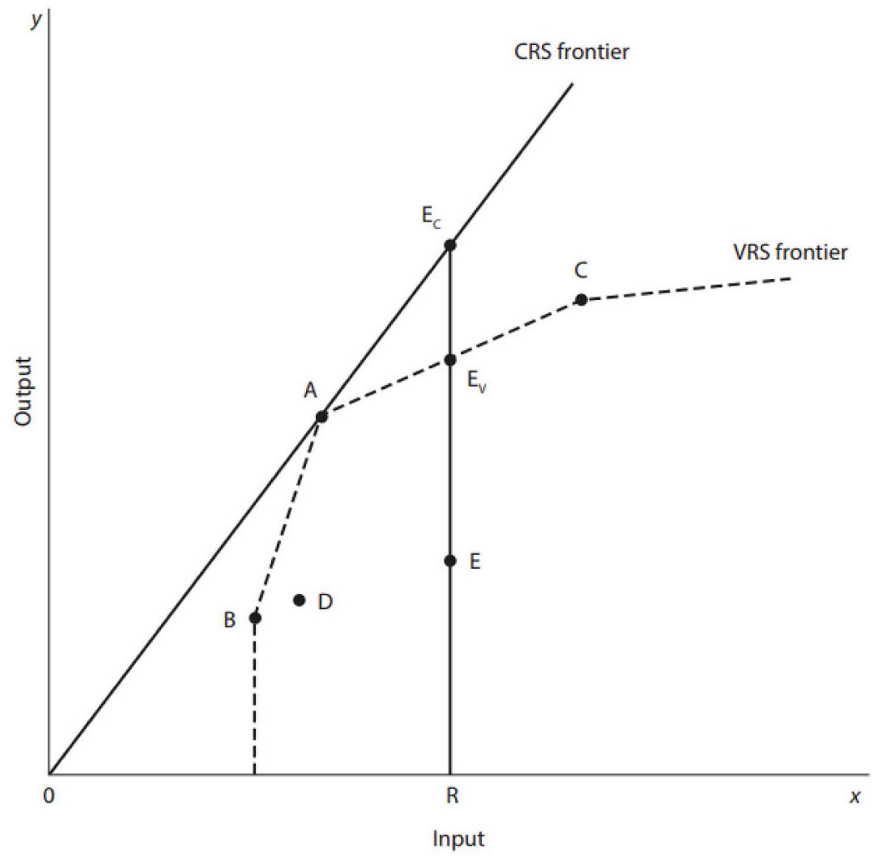

Fig. 4. Data Envelopment Analysis representation - One input, one output. Source: Herrera-Dappe and Suárez-Alemán (2016).

generation per GDP; and the share of paved roads relative to total roads. Since DEA methodology allows for multiple outputs and inputs, this exercise employs as outputs the original variables (that is, the variables that reflect access and endowment of infrastructure from the previous section). It weights all infrastructure outputs by the service quality provided (based on users' quality perceptions). ${ }^{12}$ Fig. 5 presents the conceptual framework and input and output variables included in the analysis.

Fig. 6 presents the results of an output-oriented DEA efficiency analysis assuming variable returns to scale. ${ }^{13} \mathrm{~A}$ single infrastructure production frontier for 2016 is computed to benchmark 81 countries against one another. The inclusion of 81 countries is explained by the lack of available and reliable data for other countries. Ideally, this exercise should include as many countries as possible.

As indicated before, the DEA model allows the decision-making units to reach their maximum efficiency using their most favorable weights (Wu et al., 2016). As the selection of weights is free, in many cases it implies output shares equal to 0 or 100 percent. To avoid these extreme cases, in our computations we restrict output shares to a minimum of 10 percent for each of the six economic infrastructure sectors. Therefore, in fact, the model allows the remaining shares (40 percent). This exercise is replicated for a minimum share of 15 percent for each infrastructure output and for non-constrained DEA (free weights). The results are highly correlated (0.91 with the free weights case and 0.99 with the constrained shares at 15 percent), indicating that the restrictions on output shares do not highly affect efficiency scores.

France, Germany, Japan, Moldova, ${ }^{14}$ New Zealand, Norway,

\footnotetext{
${ }^{12}$ The WEF data only includes "overall infrastructure," disaggregated data for the transport sectors (roads, railroad, port, and air transport), and electricity supply. Since there is no disaggregated data for every single sector considered, we opted to use the overall value-which refers to every infrastructure sector-and the respondent is supposed to consider all of them when answering. This data limitation should be considered by future research - when available sector-specific quality indicators at the worldwide level.

${ }^{13}$ The choice of specification depends on the conceptual framework and analytical purpose. Results from the DEA-BCC and DEA-CRS models are highly correlated in this exercise (above 0.8 ).

${ }^{14}$ The case of Moldova is particularly relevant and perfectly exemplifies the
}

Switzerland, and the United States are the top performers among the 81 countries included in the sample; Benin, Haiti, and Tanzania are the least efficient. Although there is a positive relationship between income and efficiency, being efficient is not a question of size or scale, as countries such as Moldova are as efficient as countries 90 times larger (United States), 42 times richer (Switzerland), and 3 times denser (Japan). ${ }^{15}$ Efficiency frontier analysis using variable returns to scale allows for accounting for the size effect. ${ }^{16}$ Going beyond the technicalities of the exercise, in simple terms, being more efficient means making better use of resources to produce good-quality economic infrastructure or in other words, countries that are top performers are those that have more efficient investment in infrastructure. Within LAC, Chile is the best performer but most countries in the region are concentrated in the bottom of the distribution.

Indeed, LAC performs poorly (Fig. 7). The region is on par with South Asian countries. Only Sub-Saharan African countries make worse use of existing resources.

\subsection{Is efficiency improving? Changes between 2000 and 2016}

We were able to collect input and output data back to 2000; to measure progress in efficiency we develop a single intertemporal infrastructure efficiency frontier with input and output data for 2000 and 2016. ${ }^{17}$ Fig. 8 presents the results.

Every region experienced an improvement in infrastructure efficiency between 2000 and 2016. LAC improved its average efficiency score by about 25 percent, but it lost competitiveness relative to Asia, and by 2016, South Asia had surpassed LAC. ${ }^{18}$

\section{(footnote continued)}

relative concept of efficiency. This is a lower middle-income economy, with a scarce population and medium density. When it comes to its capital stock, the country is below the fifth percentile of the sample (only exceeding Azerbaijan, Guinea, and Burundi). Yet electricity access is 100 percent, water access reaches 88.4 percent, sanitation 76.4 percent, Internet 71 percent, and 94 percent of the total road network is paved. On a scale from 1 to 7 , quality of infrastructure reaches 3.5. As efficiency is a relative concept-how much you get from what you spend-this country is well placed as it gets considerably good results with very low resources.

${ }^{15}$ Average efficiency was 83 for high-income, 57 for upper-middle-income, 45 for lower-middle-income, and 20 for low-income countries.

${ }^{16}$ Given that all variables are in ratios or percentages, potential scale effects on efficiency are with respect to values these variables take. In the case analyzed here, it is the input value (infrastructure capital stock/GDP) that varies from 1.22 to 3.3 among the LAC countries considered that determines the (increasing, constant, or decreasing) scale of infrastructure production.

${ }^{17}$ Data on the quality of infrastructure have been collected since 2005. The Global Competitiveness Report of the World Economic Forum included the following question: How would you assess general infrastructure (e.g., transport, telephony, and energy) in your country? [1 = extremely underdeveloped/among the worst in the world; $7=$ extensive and efficient/among the best in the world]. The infrastructure endowment for 2000 was then weighted by the reported perceived quality in 2005 (we may assume a lag between when the investment is done and the effect on the provision of good quality infrastructure services).

${ }^{18}$ We implemented a Malmquist decomposition to understand the role of technical progress in the productivity evolution over time. On average, Malmquist decomposition results show that technical progress over the period of analysis has been positive but low (1.6 percent for the 2000-2016 period). Several reasons may explain why this figure is quite low. First, the output in the model specification is defined as the interaction between access and quality of the main infrastructure subsectors. One should expect that the impact of technological changes is much higher on the cost of the provision of infrastructure services rather than in the development of assets - and the construction sector is a low productivity industry as reported in Barbosa et al. (2017). Secondly, with the notable exception of the telecommunications sector, and partly the energy sector, the provision of most infrastructure services in the region has not experienced notable changes over the last two decades. The technical design of road infrastructure in the region remained the same over the 

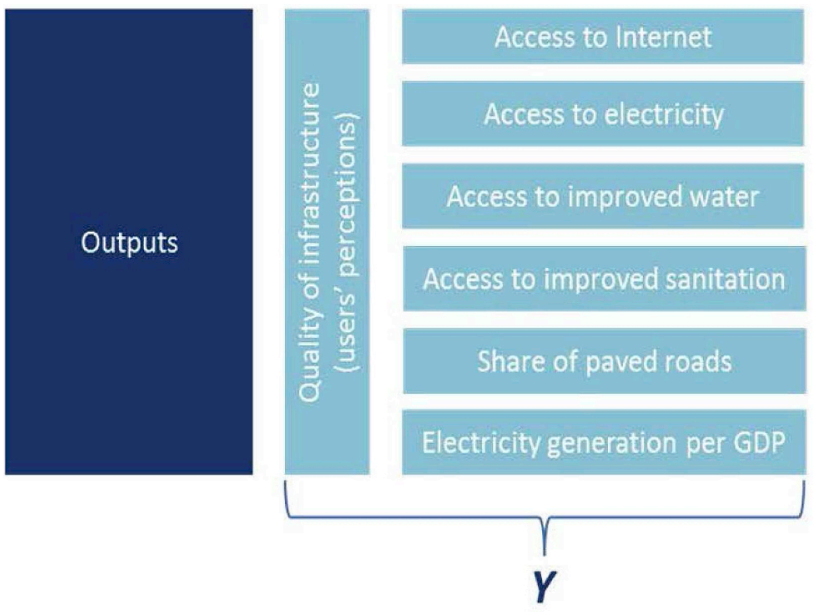

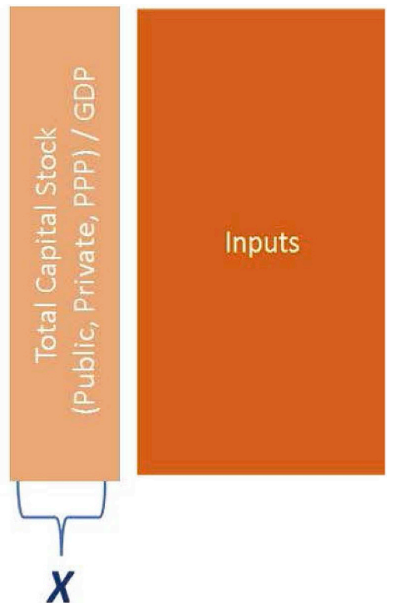

Fig. 5. Conceptual framework of infrastructure efficiency frontier.

The change in the efficiency frontier shows that most countries in LAC improved economic infrastructure efficiency over time (Fig. 9). The exception is Chile, yet it was the most efficient country in the region in 2000. ${ }^{19}$ Chile still was so in 2016, but several countries are catching up (most notably Panama). The good news in the region is that countries that were the worst performers in 2000 (Bolivia, Nicaragua, Honduras) made impressive improvements.

The relationship between efficient provision of infrastructure services and total investment is not automatic, although we should expect both variables to move close together. However, how investment and access to infrastructure translate into access and quality of services is a key driver for progress in the efficiency indicator. Bolivia and Ecuador made large investments in infrastructure over the last decade and improved their services. ${ }^{20}$ But other countries that experienced large

\section{(footnote continued)}

last twenty years, and quality improvements have been small and slow (Fay and Morrison, 2006). Studies for the port sector, such as Suárez-Alemán et al. (2016) shows how port productivity growth rates in LAC are explained by pure efficiency changes rather technological changes over the last two decades. When it comes to water provision, there has been almost no significant change over the last decades in the way the region produces (treatment plants) and distributes (traditional pipes) water. Third, when it comes to infrastructure, the literature shows the existence of a lag between technological changes and productivity improvements. As an example, Murray (2015) shows how when electricity became available in the late 1890s factory owners initially replaced their steam engines with large electric motors. Not until 20 years later they develop new factories laid out to take full advantage of the ease with which electrical power can be distributed; doubling productivity. While some sectors have experienced the recent arrival of disruptive technologies (for instance water smart metering, energy efficiency programs, transportation network companies), the full impact on productivity may take some time. Further research should explore the relationship between technology and productivity changes in the region.

${ }^{19}$ The case of Chile is explained by a decline in the perception of infrastructure quality. As the country is the top performer in the Latin America region, with high levels of access since 2000, the fall in the quality perception from 2000 to 2016 strongly affects its relative results. In a way, we could say that this is the "curse" of top performers in efficiency analysis-once you get to the top, a little fall may affect your relative position drastically.

${ }^{20}$ As an example, the progress of Bolivia is well documented. According to Infralatam (2018), a database on investments in economic infrastructure in LAC, Bolivia is the LAC country with the highest investment in infrastructure as a percentage of GDP-close to 9 percent in 2015, far from the regional average (3.5 percent between 2008 and 2015). Also, according to the IMF's Public Investment Management Efficiency Index, Bolivia is placed in the first quartile of most efficient countries, outperforming the world and regional average in each sub-index (appraisal, selection, management, and evaluation) (Dabla-Norris efficiency improvements, such as Guatemala, Honduras, and Nicaragua, did not increase their investment or did it in smaller amounts. Investment in Argentina, Brazil, and Panama decreased from 2008 to 2015, but they became more efficient in the way they produce infrastructure services with their assets (Fig. 10).

\section{Learning from best practices}

Countries can increase infrastructure efficiency by learning best practices from others and by understanding and enhancing the drivers of performance. They can use efficiency frontier analysis to set targets by benchmarking their performance against the performance of comparable countries that represent best practices.

But which is the relevant country to set benchmarks? The identification of peer groups is crucial for benchmarking. Unfortunately, the literature that has studied the efficiency of investment in infrastructure in LAC has not provided a well-justified answer. It is common to set as aspirational targets Spain and Korea. The former probably due to its historical influence in the region and its remarkable progress in developing infrastructure while the latter is due to its ability to close infrastructure gaps in a very short period. But setting countries to benchmark performance without underlying economic justification can lead to unrealistic expectations. To that end, the identification of homogenous peer groups (whom to compare with) is crucial. However, the DEA model does not account for the existing economic constraints for each country to reach a certain level of inputs (amount of total capital stock) or outputs production (high levels of quality and access provision of all infrastructure services). Well aware of this limitation, we combine the traditional DEA peer efficiency analysis with some economic rationality behind the chances of a country to reach a specific peer (a better/top performer).

There are a wide set of country characteristics that influence the ability of a country to provide high-quality infrastructure services. Certainly, many of them are institutional and summarized by lack of planning, insufficient capacity, and skills, weak transparency, or high incidence of corruption. But beyond institutional variables, there are factors that can be objectively measured and in many cases out of the immediate control of a country that allow to divide countries in groups: its economic power (income level), the size of the population it needs to serve (demand), and the economics of scale in providing infrastructure

(footnote continued)

et al., 2012). On a meta-analysis of different indicators regarding planning and project selection, Serebrisky et al. (2018) find that Bolivia is among the strongest countries in the region. 


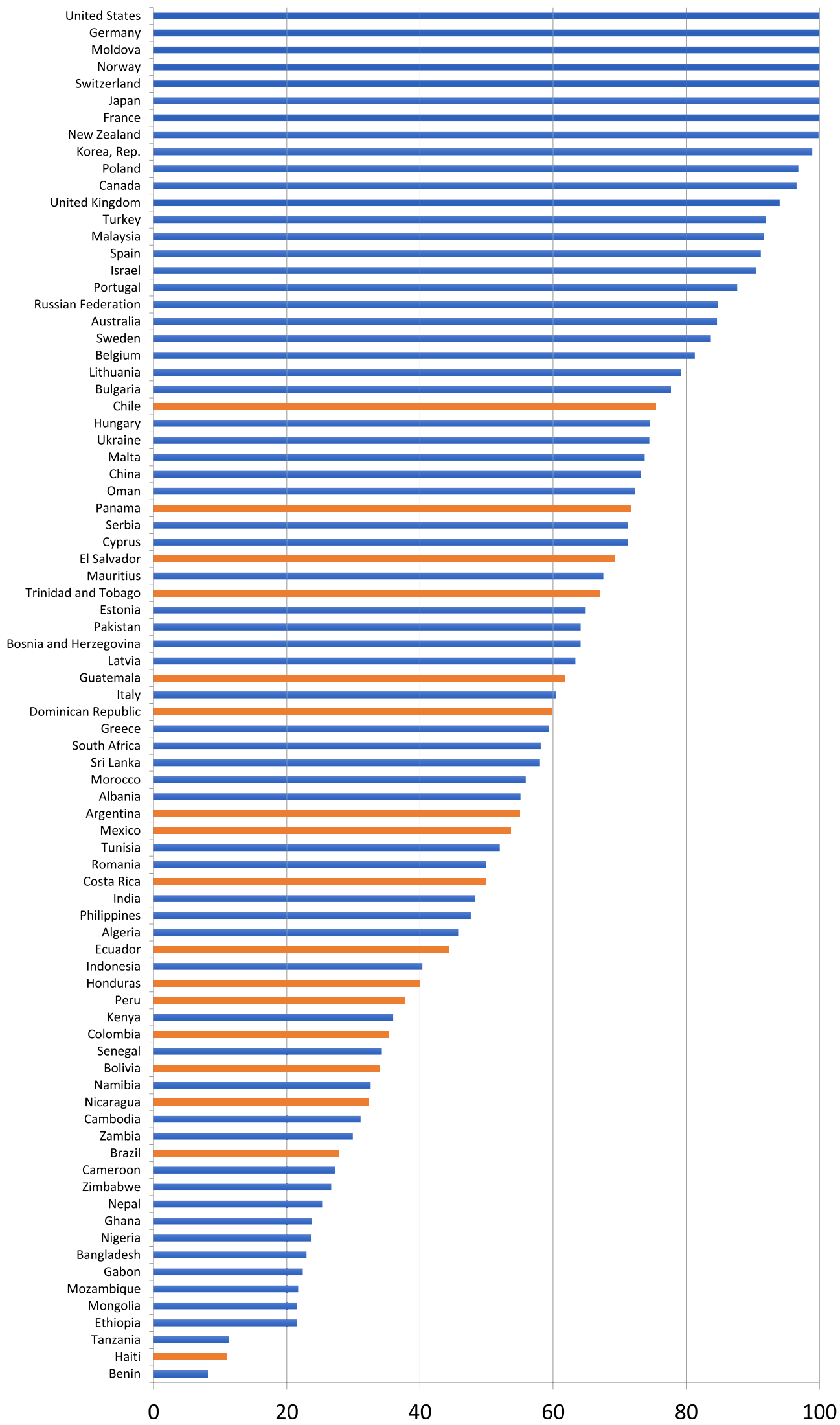

Fig. 6. Estimated infrastructure efficiency of selected countries, 2016. Source: Data from World Bank, IMF, and CIA World Factbook. Note: Countries in orange are in LAC. 


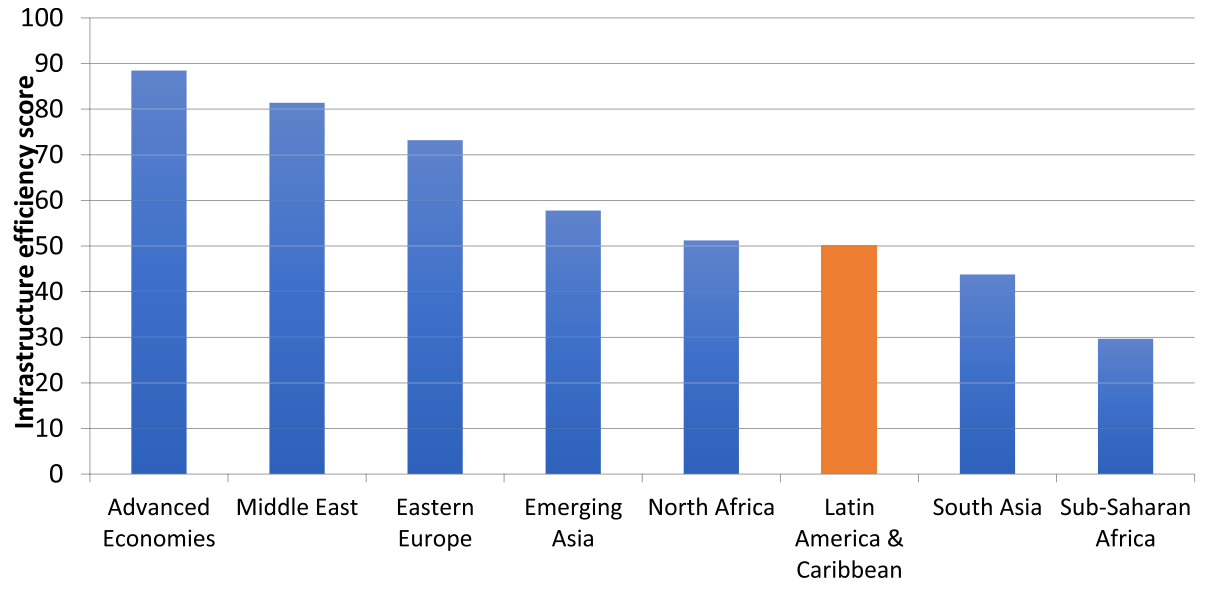

Fig. 7. Estimated infrastructure efficiency by region, 2016.

Source: Data from World Bank, IMF, and CIA World Factbook.

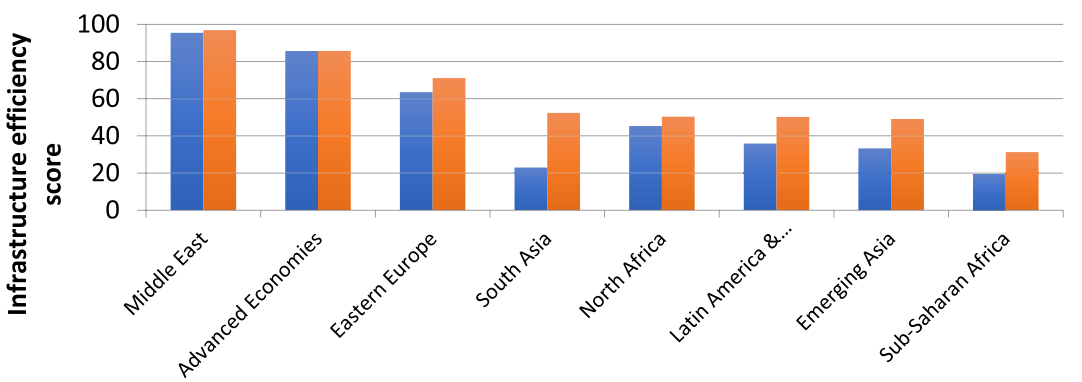

Fig. 8. Estimated infrastructure efficiency by region, 2000 and 2016.

Source: Data from World Bank, IMF, and CIA World Factbook.

te: Efficiency scores are based on the reduced sample of 52 countries (the balanced panel). The Middle East is the top-performing region because Israel is the only country in the region included in this sample.

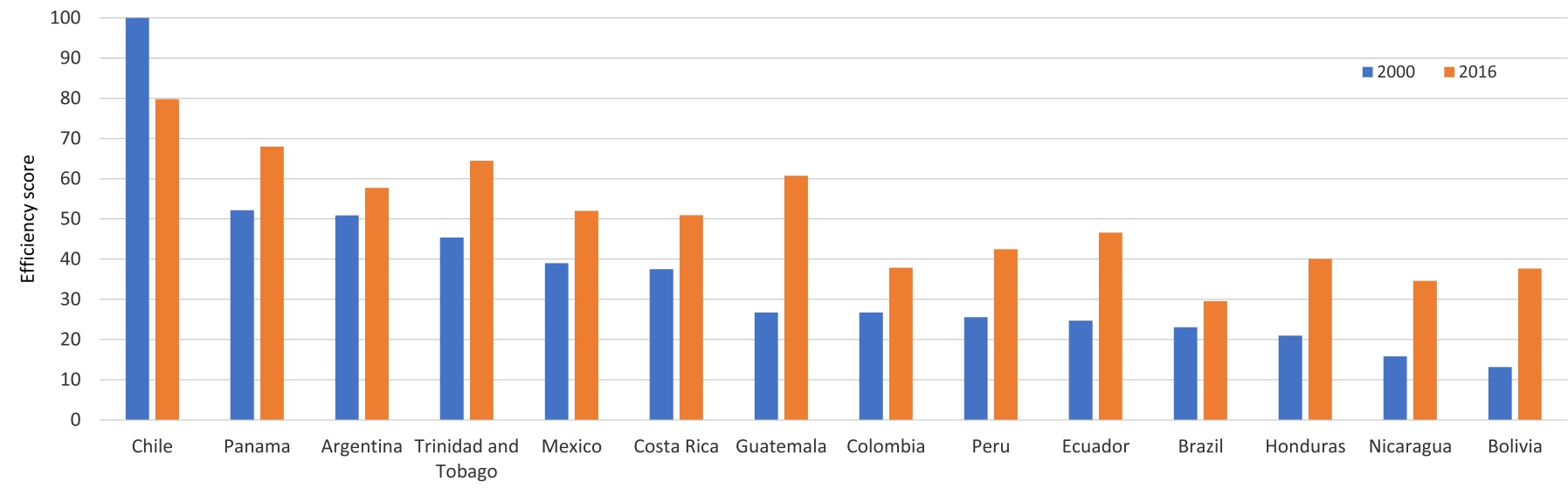

Fig. 9. Estimated infrastructure efficiency by LAC country, 2000 and 2016.

Source: Data from World Bank, IMF, and CIA World Factbook.

Note: Efficiency scores for 2016 are not the same as in the previous section because the frontier here is calculated over the reduced sample of 52 countries.

services, proxied by the density of the population (people per square kilometer). Fig. 11 summarizes the proposed conceptual framework for peer identification. The objective is to group countries as similar as possible in their income level, population, and density, and then place LAC countries within groups and identify countries within or outside the region that can serve as economically reasonable benchmarks/ peers. ${ }^{21}$

\footnotetext{
${ }^{21}$ Efficiency frontier analysis may already compare peers. And some techniques such as SFA (not suitable here due to the low number of observations) or even some DEA specifications allow for including our elements (income, population, or density) into the analysis. However, this paper attempts to respond to the need to calculate easy-to-understand and easy-to-replicate efficiency scores not affected by any other variable out of the quantity-quality-stock framework we develop in this exercise. Thus, the efficiency scores keep the essence
}

Following the peer-identification conceptual framework and relying on the 2016 DEA analysis results, Table 1 classifies LAC and most comparable peer countries by income, population, and density.

The results of the benchmarking exercise presented in Table 1 are a first step toward understanding the relative position of each country. Those results need to be complemented with in-depth country analysis. Just to provide an example, let us take the case of Colombia. In terms of

(footnote continued)

of contrasting inputs and outputs. This ex-post peer framework allows for intuitive country comparisons, but it represents an initial exercise that requires further work. Some potential avenues of research for better comparisons are the development of panel data to develop SFA or the inclusion of the proportion of urban areas by country as an alternative dimension. 


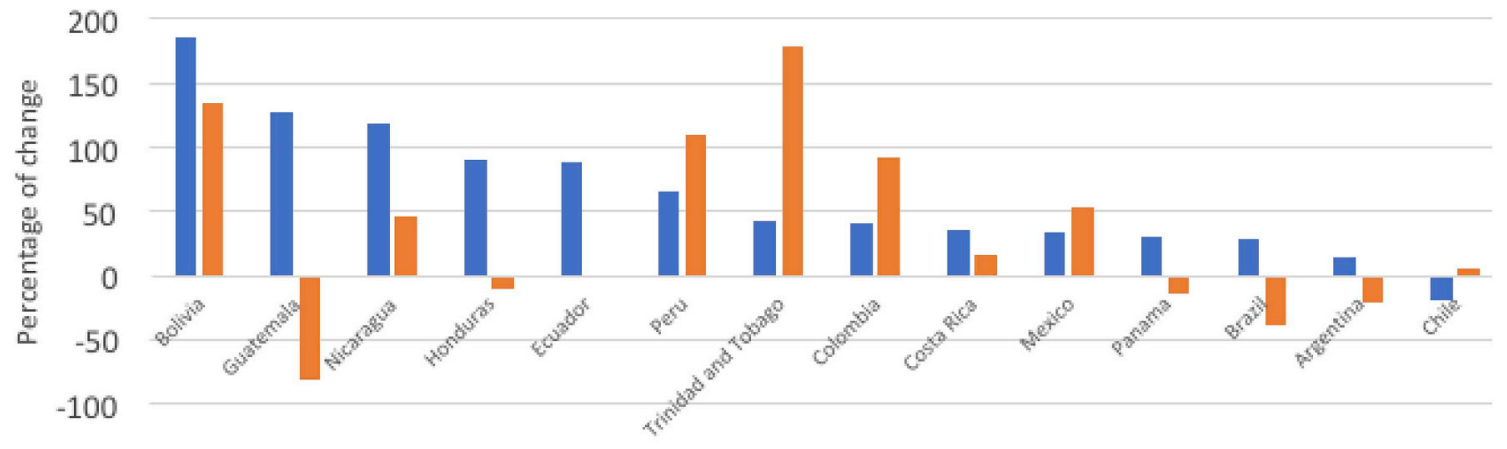

\section{q efficiency improvement $\quad$ \% investment increase}

Fig. 10. Changes in infrastructure efficiency and infrastructure investment in Latin America and the Caribbean between 2000 and 2016, by country. Source: Data from World Bank, IMF, Infralatam, and CIA World Factbook.

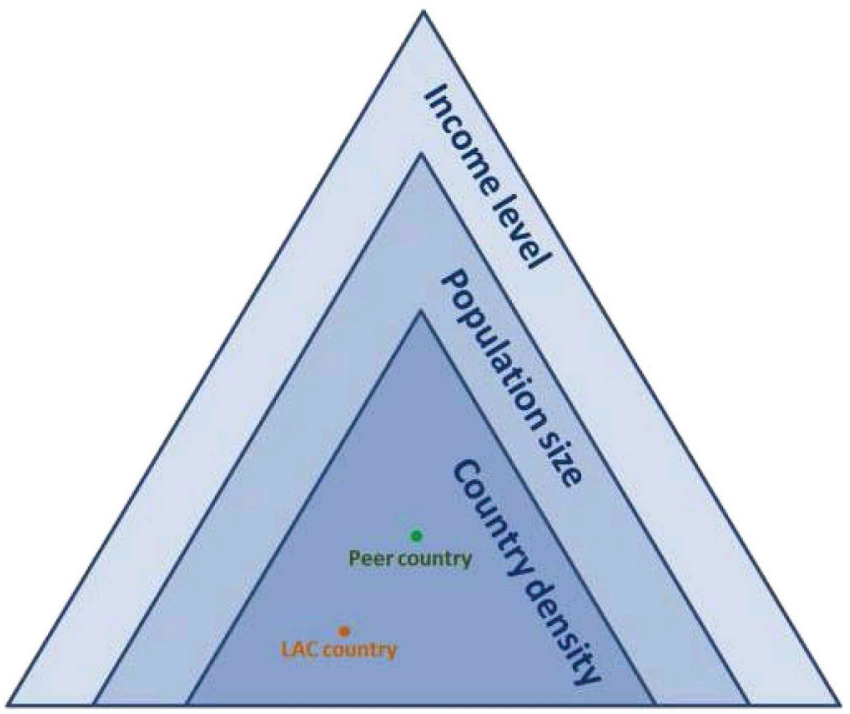

Fig. 11. Peer-identification conceptual framework. Source: Authors.

making the most of its existing assets, Colombia is lagging behind its regional benchmark, Argentina (35 percent vs. 55 percent). Access levels to infrastructure services, such as electricity, water, sanitation, and the Internet, are considerably lower in Colombia than in the southern cone country - although the quality reported is quite similar in both (about 3 on a 1 to 7 scale). But comparing with the best-performing country in Colombia's peer group (Turkey), we observe how Colombia is lagging not only in terms of access provision-particularly when it comes to paved roads-but also in terms of quality provided (Turkey scored 5 on a 1 to 7 scale), despite allocating a very similar share of its resources to the provision of infrastructure services.

The frontier and peer identification exercise opens up the possibility for policy-based questions to understand what drives the changes in the efficiency of infrastructure investment. We explore some of them. The analysis is preliminary and hopefully motivates additional research.

\section{Does better governance and regulation increase infrastructure efficiency?}

Are high levels of economic efficiency in the provision of infrastructure services related to high-quality regulation and higher government effectiveness? ${ }^{22}$ The Worldwide Governance Indicators project

\footnotetext{
${ }^{22}$ For an analysis of the effects of regulation and governance on performance,
}

reports governance indicators for more 200 countries over the period 1996-2016. This section uses its data on regulatory quality (based on perceptions of the ability of the government to formulate and implement sound policies and regulations) and government effectiveness (based on perceptions of the quality of public services, the quality of the civil service/degree of its independence from political pressures, the quality of policy formulation and implementation, and the credibility of the government's commitment to such policies, Kaufmann et al., 2010). ${ }^{23}$ Fig. 12 shows the correlations between these indexes and economic infrastructure efficiency.

Both regulatory quality and government effectiveness are highly correlated with infrastructure efficiency (Fig. 12). The correlations with regulatory quality were 0.78 in 2016 and 0.84 in 2000; the correlations with government effectiveness were 0.79 in 2016 and 0.88 in $2000 .^{24}$

In recent years, the infrastructure sector has been hard hit by corruption, particularly in LAC. ${ }^{25}$ Without action, almost $\$ 6$ trillion a year could be lost to corruption, mismanagement, and inefficiency (World Economic Forum, 2016).

To test the relationship between the rule of law and the control of corruption on infrastructure efficiency, we use data from the Worldwide Governance Indicators project. Rule of law reflects perceptions of the extent to which agents have confidence in and abide by the rules of society; the quality of contract enforcement, property rights, the police, and the courts; and the likelihood of crime and violence (Kaufmann et al., 2010). The control of corruption indicator reflects perceptions of the extent to which public power is exercised for private gain, including both petty and grand forms of corruption, and the "capture" of the state by elites and private interests. Both variables are positively correlated with the infrastructure efficiency indicator (the correlation for the first measures is 0.67 for 2016 and 0.84 for 2000; the correlation for the second measure is 0.71 for 2016 and 0.83 for 2000). These results

\section{(footnote continued)}

see Estache and Rossi (2002) and Estache et al. (2004) for electricity; Estache et al. (2002) for transport; Estache and Rossi (2002) for water; and Da Motta and Moreira (2006) for sanitation.

${ }^{23}$ These indicators are based on more than 30 underlying data sources reporting the perceptions of governance of a large number of survey respondents and expert assessments worldwide (World Economic Forum, 2016). For details on the underlying data sources, the aggregation method, and the interpretation of the indicators, see Kaufmann et al. (2010). Data for 2016 can be found at http:// info.worldbank.org/governance/wgi/index.aspx\#home.

${ }^{24} \mathrm{An}$ important matter for future research is the development of the right policies and instruments to improve infrastructure governance. Some key recent references in this area for the LAC region are Andrés et al. (2013), Fay et al. (2017), and Jaimurzina and Sánchez (2017).

${ }^{25}$ Kenny (2009) reviews the evidence on corruption in infrastructure in transition economies and developing countries. 
Table 1

Suggested peers for countries in Latin America and the Caribbean, 2016.

Source: Data from World Bank, IMF, and CIA World Factbook.

\begin{tabular}{|c|c|c|c|c|}
\hline Country & Income level $^{\mathrm{b}}$ & Population size $^{c}$ & Density $^{\mathrm{d}}$ & Efficiency score \\
\hline Norway & High & Small & Low & 100 \\
\hline Australia & High & Small & Very low & 85 \\
\hline Sweden & High & Small & Low & 84 \\
\hline Chile & High & Small & Low & 75 \\
\hline Sweden & High & Small & Low & 84 \\
\hline Malta & High & Very small & Very high & 74 \\
\hline Cyprus & High & Very small & Medium & 71 \\
\hline Trinidad and Tobago & High & Very small & High & 67 \\
\hline Russian Federation & Upper middle & Big & Very low & 85 \\
\hline China & Upper middle & Huge & Medium & 73 \\
\hline Mexico & Upper middle & Big & Low & 54 \\
\hline Brazil & Upper middle & Big & Low & 28 \\
\hline Turkey & Upper middle & Medium & Medium & 92 \\
\hline Malaysia & Upper middle & Medium & Medium & 92 \\
\hline South Africa & Upper middle & Medium & Low & 58 \\
\hline Argentina & Upper middle & Medium & Low & 55 \\
\hline Algeria & Upper middle & Medium & Low & 46 \\
\hline Peru & Upper middle & Medium & Low & 38 \\
\hline Colombia & Upper middle & Medium & Low & 35 \\
\hline Bulgaria & Upper middle & Small & Low & 78 \\
\hline Serbia & Upper middle & Small & Medium & 71 \\
\hline Dominican Republic & Upper middle & Small & High & 60 \\
\hline Romania & Upper middle & Small & Medium & 50 \\
\hline Ecuador & Upper middle & Small & Low & 44 \\
\hline Mauritius & Upper middle & Very small & High & 68 \\
\hline Albania & Upper middle & Very small & Medium & 55 \\
\hline Costa Rica & Upper middle & Very small & Medium & 50 \\
\hline Panama & Upper middle & Very small & Low & 72 \\
\hline Bosnia and Herzegovina & Upper middle & Very small & Low & 64 \\
\hline El Salvador & Lower middle & Small & High & 69 \\
\hline Guatemala & Lower middle & Small & Medium & 62 \\
\hline Sri Lanka & Lower middle & Small & High & 58 \\
\hline Honduras & Lower middle & Small & Medium & 40 \\
\hline Cambodia & Lower middle & Small & Medium & 31 \\
\hline Ghana & Lower middle & Small & Medium & 24 \\
\hline Tunisia & Lower middle & Small & Low & 52 \\
\hline Bolivia & Lower middle & Small & Very low & 34 \\
\hline Senegal & Low & Small & Medium & 34 \\
\hline Nepal & Low & Small & High & 25 \\
\hline Haiti & Low & Small & High & 11 \\
\hline
\end{tabular}

Note: Table shows only categories that include a LAC country. See Appendix Table A.3 for the full list.

a Suggested cut-offs for groups of countries included in each box (colors) are defined by considering those countries with the same income and population levels and with identical or very similar (those having the next greater or lesser degree) density level.

b Income levels are defined by the World Bank, based on per capita Gross National Income (GNI) in 2015. The cut-offs are as follows: low: \$1025 or less; lowermiddle: \$1026-\$4035; upper-middle: \$4036-\$12,475; high: \$12,476 or more.

c Population groups are defined as follows: very small: fewer than 5 million people; small: 5-30 million; medium: 30-100 million; big: 100-400 million; huge: more than 1 billion.

d Density groups are defined as follows: very low: fewer than 10 people per square kilometer; low: 10-80; medium: 80-200; big: 200-1000; huge: more than 1000 people.

signal potential infrastructure efficiency gains by strengthening the fight against corruption (Fig. 13).

\section{Policy implications}

Latin American and Caribbean countries are not sufficiently efficient when it comes to the provision of infrastructure services. This constitutes the main conclusion derived from the present study. LAC countries currently present efficiency levels below 50 percent. This means that the region could, in theory, double output (that is, the provision of different economic infrastructure services) with the same resources used today. Our findings also confirm that, faced with the persistently unfulfilled promise of much more investment, the most fruitful way to close the infrastructure services gap in the region today may be to focus on improving the efficiency in the sector.

LAC has worked hard to improve the quality and access to infrastructure services over the past few decades. Differences across subregions and countries are narrowing, as all countries have closed some of the most urgent access gaps, especially in electricity, water, and sanitation. Service provision is still far lower than in other regions, however. LAC performs much worse than advanced economies, and the gap between LAC and emerging economies and South Asian countries is wider than it was two decades ago. The quality of infrastructure services in most LAC countries has declined since 2010 (the Dominican 


\section{a. Infrastructure efficiency and regulatory quality (2016)}

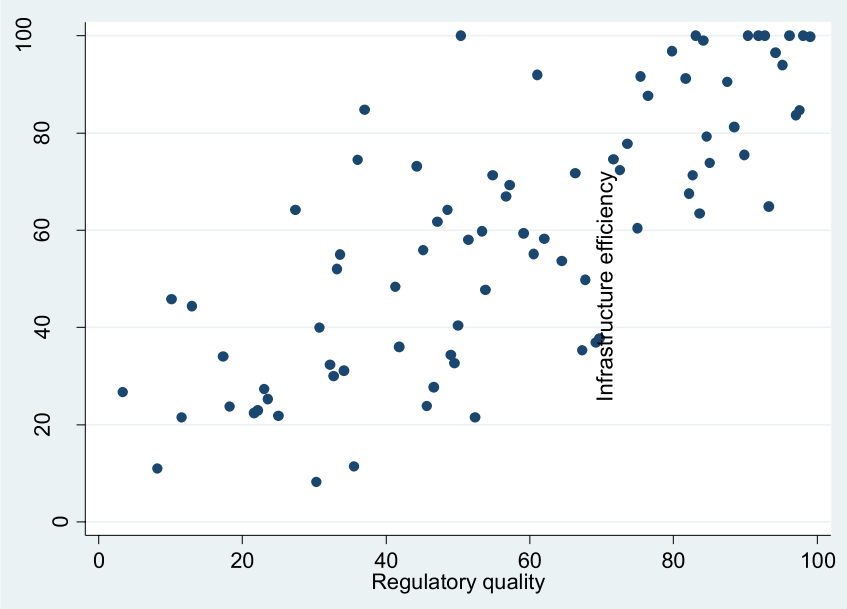

\section{b. Infrastructure efficiency and government} effectiveness (2016)

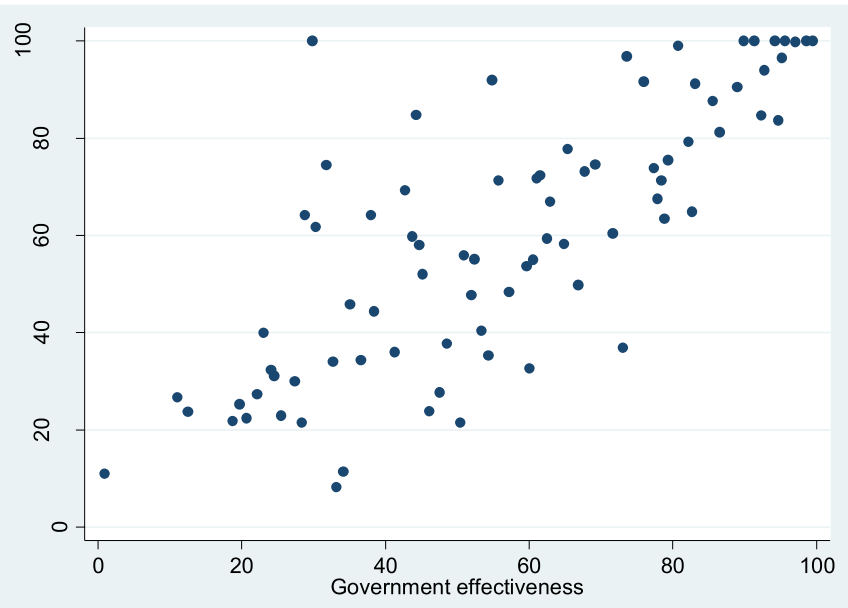

Fig. 12. Correlation between infrastructure efficiency, regulation, and governance indicators. Source: Data from World Bank, IMF, Kaufmann et al. (2010), and CIA Factbook.

\section{a. Infrastructure efficiency and rule of law} (2016)

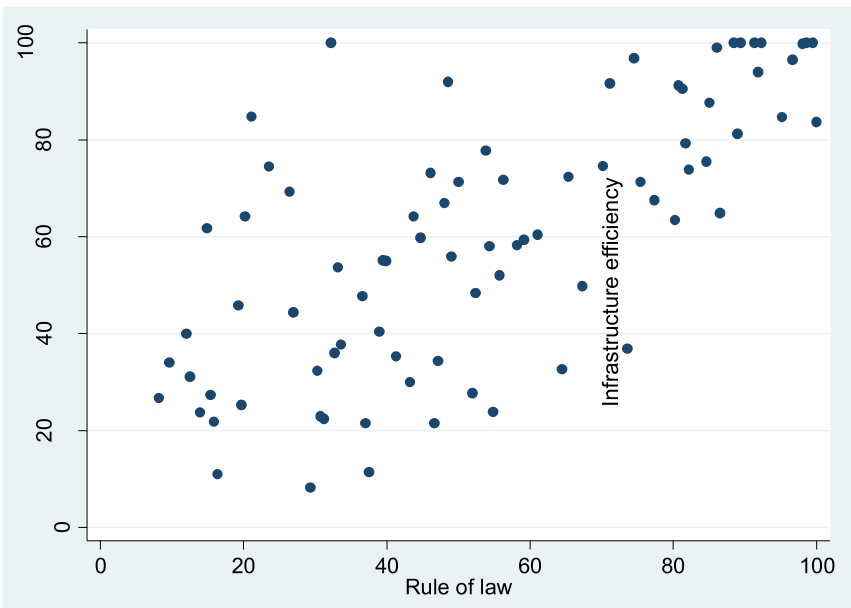

\section{b. Infrastructure efficiency and control of corruption (2016)}

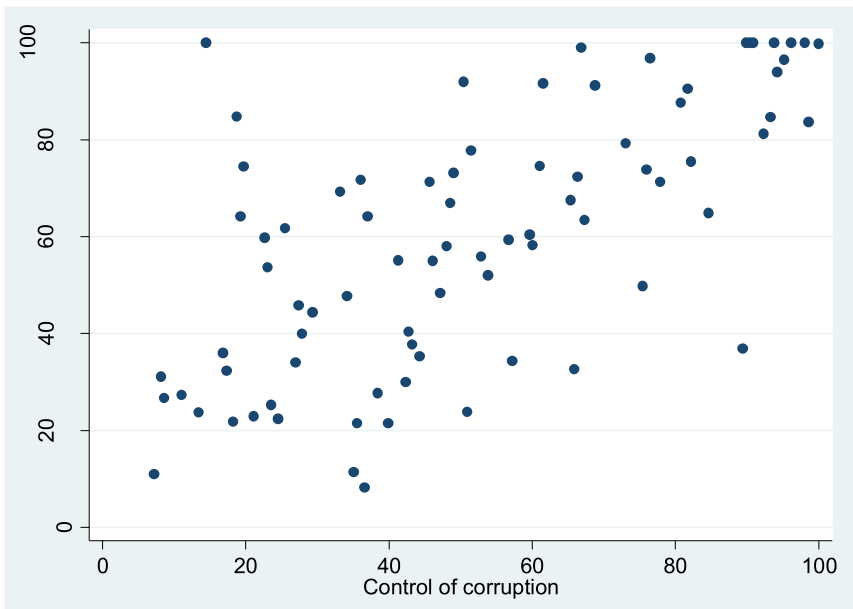

Fig. 13. Correlation between infrastructure efficiency and the rule of law and corruption.

Source: Data from World Bank, IMF, and CIA Factbook.

Republic, Panama, and Mexico are notable exceptions). There are some success stories in the region. Bolivia, Ecuador, and Nicaragua improved efficiency, mainly through massive and effective investment over the last decade. Guatemala and Honduras improved efficiency despite cuts in investment, proving that efficiency is not only a matter of more resources.

How to improve and keep improving necessarily involves learning from others' successful practices. In turn, this requires being able to identify what and who to learn from. In the search of a methodology to identify comparable peers for LAC, we developed a peer identification framework based on income, population, density, and DEA results. This exercise allows us to match up comparable countries in a way that LAC countries are able to look at the experiences of other countries facing similar problems and demands for infrastructure services, even though the other countries might be outperforming them in terms of efficiency.
In so doing, as an example, Chile may find how Norway or Australia constitute reasonable international peers, while Ecuador might learn from the Bulgarian experience, and Bolivia may gain from the case of Tunisia.

Last but not least, it is useful to recall the role of some "usual suspects" as drivers of infrastructure performance in a country, that is, regulatory quality and government effectiveness. Globally, infrastructure efficiency is highly correlated with the ability of governments to develop sound policies and regulations, the quality of policy formulation and implementation, and governments' credibility. Reducing corruption, which remains a formidable problem in the region, is critical to increasing the efficiency of infrastructure. On this matter, our research could constitute a starting point for modeling that quantifies the gains from reducing corruption and improving the regulatory and governance frameworks of the infrastructure sector. 


\section{Appendix A}

Table A1

A sample of sector-based infrastructure efficiency analysis.

\begin{tabular}{|c|c|c|}
\hline Sector & Paper & Main results \\
\hline Electricity & Damonte et al. (2012) & Average efficiency scores of 74-93 percent (depending on the methodology used) for 61 electricity distributors in Brazil. \\
\hline Electricity & $\begin{array}{l}\text { Oliveira and Tostes } \\
\text { (2017) }\end{array}$ & $\begin{array}{l}\text { Best performance projects of the energy-efficiency program in Brazil's electricity distribution sector was achieved by projects representing five } \\
\text { percent of total investments. Top performers were in the industrial and cogeneration categories. }\end{array}$ \\
\hline Electricity & $\begin{array}{l}\text { Pombo and Taborda } \\
\text { (2006) }\end{array}$ & $\begin{array}{l}\text { Efficiency levels of distribution companies in Colombia improved and the efficient distributors, which are the larger utilities, remain on the } \\
\text { best practice frontier. Inefficient power distributors remain, however, and they became less efficient after } 1995 .\end{array}$ \\
\hline Telecom & Llungo-Ortiz (2014) & $\begin{array}{l}\text { The author evaluates the efficiency of the telecommunications sector in Latin America at the regional, country, and firm levels. He finds that } \\
\text { privatization and technological advances improved service quality, efficiency, and productivity. }\end{array}$ \\
\hline Airports & Serebrisky (2012) & $\begin{array}{l}\text { LAC airports are less efficient than airports in Asia and North America. The technical efficiency of LAC airports varies widely. Six of the } 22 \text { LAC } \\
\text { airports in the sample are on the efficiency frontier. On average, LAC airports are } 69 \text { percent as efficient as the most efficient airport. }\end{array}$ \\
\hline Ports & $\begin{array}{l}\text { Suárez-Alemán et al. } \\
\text { (2016) }\end{array}$ & $\begin{array}{l}\text { Ports in LAC are far less efficient than the top-performing Chinese ports. They show that private sector participation, the reduction of } \\
\text { corruption in the public sector, improvements in liner connectivity, and the existence of multimodal links increase the level of port efficiency in } \\
\text { developing regions. }\end{array}$ \\
\hline Ports & $\begin{array}{l}\text { Serebrisky et al. } \\
(2016)\end{array}$ & Average technical efficiency of ports in LAC rose from 52 percent in 1999 to 64 percent in 2009. \\
\hline Airlines & Wanke et al. (2016) & $\begin{array}{l}\text { Authors find high levels of efficiency in LAC airlines ( } 75-82 \text { percent). They also report that public ownership is related to higher levels of } \\
\text { efficiency in the region, probably because of higher entrance barriers to launching an airline in those countries. }\end{array}$ \\
\hline Roads & Braconier et al. (2013) & $\begin{array}{l}\text { Authors assess the efficiency of road transport in } 32 \text { OECD countries, including Chile and Mexico. They show that efficiency could be improved } \\
\text { by } 5-25 \text { percent. }\end{array}$ \\
\hline Water & Ferro et al. (2011) & LAC average efficiency rates of $42-48$ percent. \\
\hline Water & $\begin{array}{l}\text { Bonifaz and Barboza } \\
\text { (2014) }\end{array}$ & $\begin{array}{l}\text { Private companies outperform public companies. Inefficiency is positively correlated with firm size and the length of a network. On average, } \\
\text { inefficiency adds } 32 \text { percent to the costs of Latin American water companies. }\end{array}$ \\
\hline Water & Da Silva et al. (2007) & They find no evidence that private firms and public firms differ significantly in terms of efficiency in Brazil. \\
\hline Water & Ferro et al. (2014) & Authors find that inefficiency in the water and sanitation sectors decreased by 4.9 percent a year in the period of analysis. \\
\hline
\end{tabular}

Source: authors.

Table A2

Investment in infrastructure as percent of gross fixed capital formation in selected countries in Latin America and the Caribbean

\begin{tabular}{|c|c|c|c|c|}
\hline \multirow[t]{2}{*}{ Country } & \multicolumn{2}{|c|}{ 1980-2012 } & \multicolumn{2}{|l|}{$2000-12$} \\
\hline & Average & Standard deviation & Average & Standard deviation \\
\hline Argentina & 20.4 & 10.3 & 15.6 & 5.1 \\
\hline Brazil & 20.8 & 9.2 & 18.2 & 6.6 \\
\hline Chile & 17.6 & 8.5 & 14.5 & 5.8 \\
\hline Colombia & 17.2 & 5.3 & 13.5 & 3.8 \\
\hline Mexico & 11.3 & 4.2 & 10.5 & 3.8 \\
\hline Peru & 10.4 & 5.5 & 15.0 & 3.3 \\
\hline
\end{tabular}

Source: Data from World Bank (2018) and Calderón and Servén (2003).

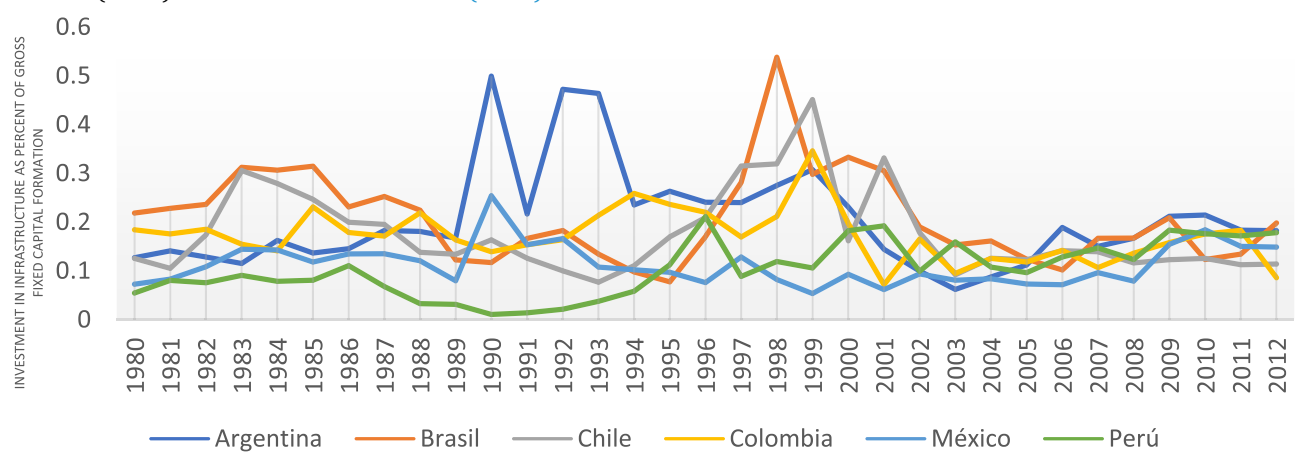

Fig. A.1. Investment in infrastructure as percent of gross fixed capital formation in selected countries in Latin America and the Caribbean Source: Data from World Bank (2018) and Calderón and Servén (2003). 


\section{a. Electricity}

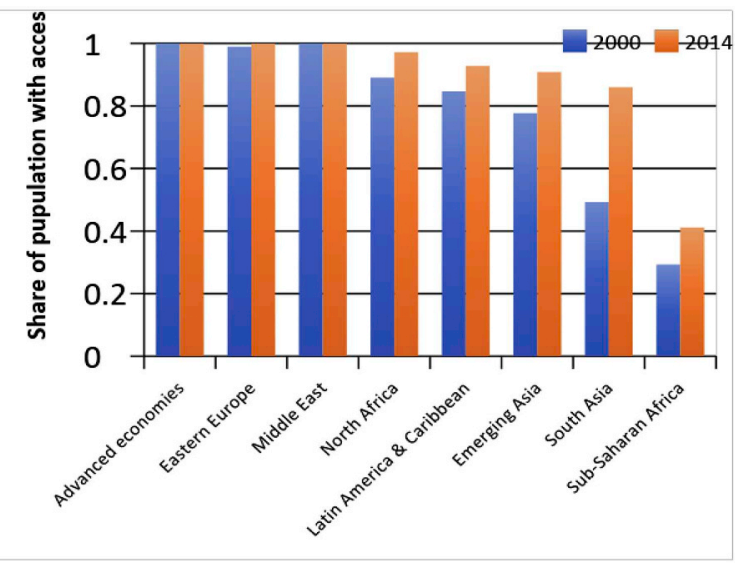

\section{c. Improved water}

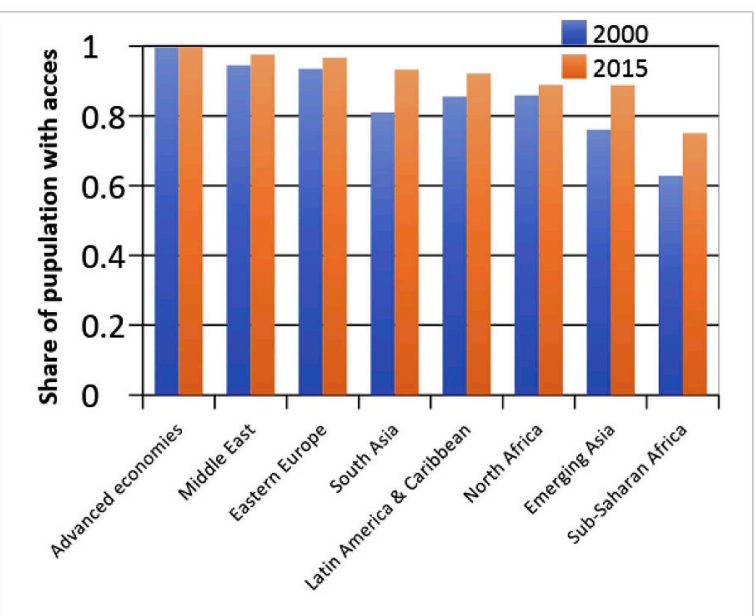

\section{b. Improved sanitation}

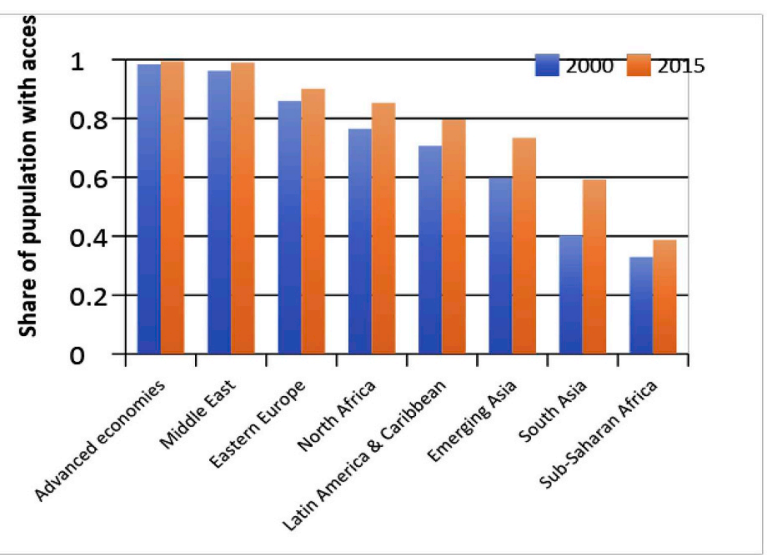

d. Internet

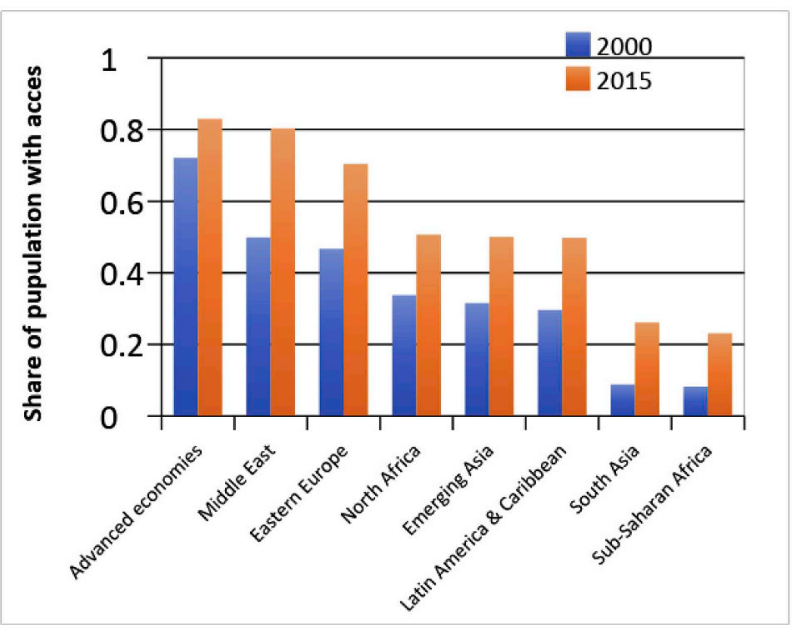

Fig. A2a. Access to infrastructure services by region, 2000 and 2015.

Source: World Bank database.

Note: In panel a, data shown by the orange bars are for the most recent available data (2014 for electricity).

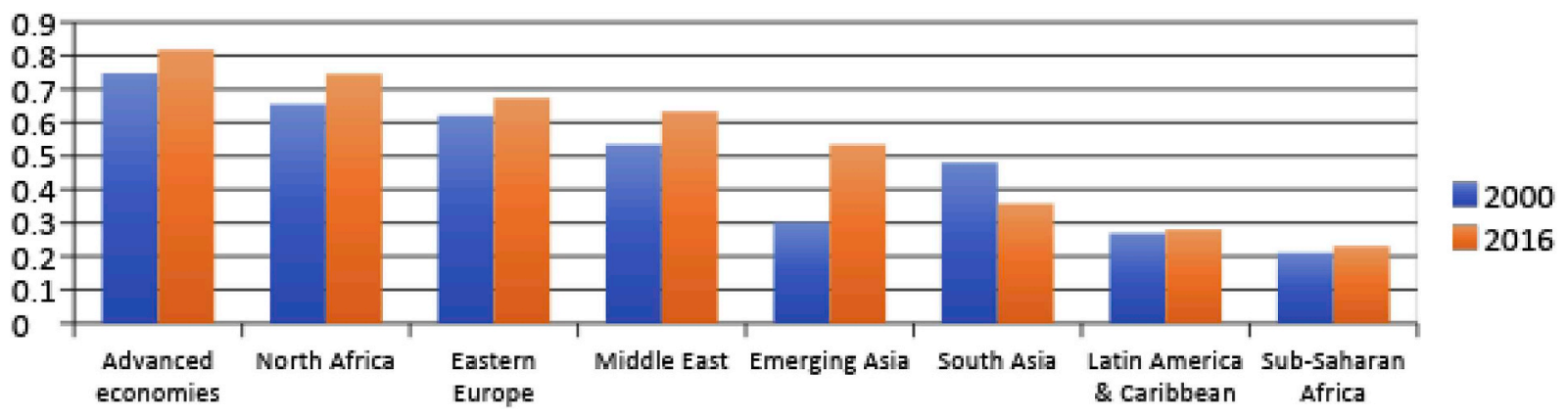

Fig. A2b. Share of paved roads in the road network, by region, 2000 and 2016.

Source: CIA World Factbook data.

Note: Algeria (77 percent) and Tunisia (76 percent) explain the high value of the North Africa region when it comes to paved roads as a share of total roads.

Table A.3

Infrastructure index (results of Principal Component Analysis). 
2016 data

\begin{tabular}{|c|c|c|c|c|}
\hline ncipal compone & /covariance & pa1) & $\begin{array}{l}\text { Number of obs } \\
\text { Number of comp. } \\
\text { Trace } \\
\text { Rho }\end{array}$ & $\begin{array}{rr}= & 103 \\
= & 1 \\
= & 123229.7 \\
= & 0.8870\end{array}$ \\
\hline Component. & Eigenvalue & Difference & Proportion & Cumulative \\
\hline Comp1 & 109308 & 100170 & 0.8870 & 0.8870 \\
\hline Comp2 & 9137.77 & 6765.56 & 0.0742 & 0.9612 \\
\hline Comp3 & 2372.22 & 1069.2 & 0.0193 & 0.9804 \\
\hline Comp4 & 1303.01 & 194.441 & 0.0106 & 0.9910 \\
\hline Comp5 & 1108.57 & . & 0.0090 & 1.0000 \\
\hline
\end{tabular}

Note: Correlations between Comp1 and infrastructure quantity-quality variables are 0.96 (energy), 0.95 (telecom), 0.86 (transport), 0.97 (sanitation), and 0.96 (water).

2000 data

Principal components/covariance

\begin{tabular}{rrrrr}
\hline Component & Eigenvalue & Difference & Proportion & Cumulative \\
\hline Comp1 & 120649 & 114026 & 0.9000 & 0.9000 \\
Comp2 & 6622.54 & 2977.19 & 0.0494 & 0.9494 \\
Comp3 & 3645.35 & 1569.46 & 0.0272 & 0.9766 \\
Comp4 & 2075.89 & 1015.56 & 0.0155 & 0.9921 \\
Comp5 & 1060.33 &. & 0.0079 & 1.0000 \\
\hline
\end{tabular}

PCA normalized results, by country

\begin{tabular}{|c|c|c|c|}
\hline Country & $\begin{array}{l}\text { Normalized } \\
\text { PCA score }\end{array}$ & Country & $\begin{array}{l}\text { Normalized } \\
\text { PCA score }\end{array}$ \\
\hline Switzerland & 1.00 & Bosnia and Herzegovina & 0.43 \\
\hline Japan & 0.92 & Vietnam & 0.43 \\
\hline France & 0.91 & Serbia & 0.42 \\
\hline Germany & 0.91 & Algeria & 0.42 \\
\hline Spain & 0.87 & Dominican Republic & 0.42 \\
\hline Korea, Rep. & 0.83 & Costa Rica & 0.41 \\
\hline United Kingdom & 0.83 & Guatemala & 0.40 \\
\hline Portugal & 0.82 & Bhutan & 0.40 \\
\hline Malaysia & 0.81 & Indonesia & 0.39 \\
\hline Bahrain & 0.80 & Argentina & 0.37 \\
\hline United States & 0.80 & Honduras & 0.37 \\
\hline Belgium & 0.79 & Pakistan & 0.37 \\
\hline Norway & 0.76 & India & 0.36 \\
\hline Sweden & 0.73 & Philippines & 0.35 \\
\hline Canada & 0.73 & Colombia & 0.34 \\
\hline New Zealand & 0.71 & Brazil & 0.32 \\
\hline Lithuania & 0.70 & Namibia & 0.32 \\
\hline Turkey & 0.69 & Peru & 0.31 \\
\hline Australia & 0.66 & Swaziland & 0.31 \\
\hline Seychelles & 0.66 & Bolivia & 0.29 \\
\hline Israel & 0.65 & Senegal & 0.29 \\
\hline Malta & 0.65 & Paraguay & 0.28 \\
\hline Cyprus & 0.65 & Gambia, The & 0.28 \\
\hline Estonia & 0.64 & Nicaragua & 0.28 \\
\hline Mauritius & 0.64 & Rwanda & 0.28 \\
\hline Oman & 0.64 & Gabon & 0.27 \\
\hline Hungary & 0.62 & Mongolia & 0.25 \\
\hline Azerbaijan & 0.62 & Nepal & 0.24 \\
\hline Saudi Arabia & 0.62 & Cambodia & 0.22 \\
\hline Kazakhstan & 0.61 & Ghana & 0.21 \\
\hline Italy & 0.60 & Bangladesh & 0.21 \\
\hline Latvia & 0.59 & Kenya & 0.21 \\
\hline China & 0.58 & Lesotho & 0.21 \\
\hline Trinidad and Tobago & 0.57 & Zambia & 0.20 \\
\hline Poland & 0.57 & Cameroon & 0.20 \\
\hline Chile & 0.56 & Zimbabwe & 0.17 \\
\hline Greece & 0.55 & Uganda & 0.16 \\
\hline Russian Federation & 0.55 & Malawi & 0.16 \\
\hline Panama & 0.54 & Mali & 0.16 \\
\hline Ukraine & 0.53 & Nigeria & 0.15 \\
\hline Sri Lanka & 0.53 & Mauritania & 0.14 \\
\hline Morocco & 0.53 & Ethiopia & 0.14 \\
\hline Bulgaria & 0.52 & Burundi & 0.12 \\
\hline Ecuador & 0.50 & Benin & 0.11 \\
\hline Albania & 0.49 & Mozambique & 0.11 \\
\hline Mexico & 0.49 & Haiti & 0.10 \\
\hline Tunisia & 0.48 & Liberia & 0.10 \\
\hline Moldova & 0.48 & Tanzania & 0.10 \\
\hline Romania & 0.45 & Guinea & 0.09 \\
\hline El Salvador & 0.45 & Madagascar & 0.08 \\
\hline Uruguay & 0.44 & Sierra Leone & 0.07 \\
\hline South Africa & 0.43 & & \\
\hline
\end{tabular}




\section{References}

Abdi, H., Williams, L.J., 2010. Principal component analysis. Wiley Interdisciplinary Reviews: Comput. Stat. 2 (4), 433-459.

Andres, L., 2007. Assessing the Governance of Electricity Regulatory Agencies in the Latin American and Caribbean Region: A Benchmarking Analysis. World Bank, Washington, DC.

Andrés, Luis A., Schwartz, Jordan, Luis Guasch, J., 2013. Uncovering the Drivers of Utility Performance: Lessons from Latin America and the Caribbean on the Role of the Private Sector, Regulation, and Governance in the Power, Water, and Telecommunication Sectors. The World Bank 2013.

Banker, R.D., Charnes, A., Cooper, W.W., 1984. Some models for estimating technical and scale inefficiencies in data envelopment analysis. Manag. Sci. 3 (9), 1078-1092.

Barbosa, F., Woetzel, J., Mischke, J., Ribeirinho, M.J., Sridhar, M., Parsons, M., Bertram, N., Brown, S., 2017. Reinventing Construction: A Route to Higher Productivity. McKinsey Global Institute.

Bhattacharya, A., Romani, M., Stern, N., 2012. Infrastructure for Development: Meeting the Challenge. Centre for Climate Change Economics and Policy, London.

Bonifaz, J.L., Barboza, R.I., 2014. "An Analysis of Inefficiency of Big Urban Water Utilities in Latin America." Documento de Discusión CIP DD1413. Universidad Del Pacifico, Lima.

Calderón, C., Servén, L., 2003. "The output cost of Latin America's infrastructure gap. In: The Limits of Stabilization: Infrastructure, Public Deficits, and Growth in Latin America, pp. 95-118.

Carranza, L., Daude, C., Melguizo, A., 2014. Public infrastructure investment and fisca sustainability in Latin America: incompatible goals? J. Econ. Stud. 41 (1), 29-50.

Cavallo, E.A., Powell, A., 2018. Informe Macroeconomico de América Latina y el Caribe 2018: La Hora Del Crecimiento. (Macroeconomic Report on Latin America and the Caribbean, 2018: The Time of Growth.).

Cavallo, E., Serebrisky, Tomas (Eds.), 2016. Saving for Development: How Latin America and the Caribbean Can Save More and Better. Inter-American Development Bank, Washington DC.

Cerra, V., Cuevas, A., Góes, C., Karpowicz, I., Matheson, T., Samaké, I., Vtyurina, S., 2016. Highways to Heaven: Infrastructure Determinants and Trends in Latin America and the Caribbean." Working Paper WP/16/185. International Monetary Fund, Washington, DC.

Charnes, A., Cooper, W.W., Rhodes, E., 1978. Measuring the efficiency of decision making units. Eur. J. Oper. Res. 2 (6), 429-444.

Coelli, T.J., Rao, D.S.P., O'Donnell, C.J., Battese, G.E., 2005. An Introduction to Efficiency and Productivity Analysis. Springer Science \& Business Media.

Dabla-Norris, E., Brumby, J., Kyobe, A., Mills, Z., Papageorgiou, C., 2012. Investing in public investment: an index of public investment efficiency. J. Econ. Growth 17 (3), 235-266.

Damonte, F., De Santis, M., Berg, S., 2012. The efficiency of Brazilian electricity distributors during 2004-2009: an application using DEA corrected by environmental and stochastic factors. In: Data Envelopment Analysis: Theory and Applications.

Da Silva, E., Souza, G., De Faria, R.C., Moreira, T.B.S., 2007. Estimating the relative ef ficiency of Brazilian publicly and privately owned water utilities: a stochastic cost frontier approach. J. Am. Water Resour. Assoc. 43 (5), 1237-1244.

Da Motta, R.S., Moreira, A., 2006. Efficiency and regulation in the sanitation sector in Brazil. Util. Pol. 14 (3), 185-195.

Estache, A., Rossi, M.A., 2002. How different is the efficiency of public and private water companies in Asia? World Bank Econ. Rev. 16 (1), 139-148.

Estache, A., Rossi, M.A., Ruzzier, C.A., 2004. The case for international coordination of electricity regulation: evidence from the measurement of efficiency in South America. J. Regul. Econ. 25 (3), 271-295.

Fay, M., Morrison, M., 2006. Infrastructure in Latin America and the Caribbean: Recent Developments and Key Challenges. The World Bank.

Fay, M., Alberto Andres, L., Fox, C., Narloch, U., Straub, S., Slawson, M., 2017. Rethinking Infrastructure in Latin America and the Caribbean: Spending Better to Achieve More. The World Bank.

Ferro, G., Lentini, E.J., Mercadier, A.C., Romero, C.A., 2014. "Efficiency in Brazil's water and sanitation sector and its relationship with regional provision, property and the independence of operators. Util. Pol. 28, 42-51.
Ferro, G., Romero, C.A., Covelli, M.P., 2011. Regulation and performance: a production frontier estimate for the Latin American water and sanitation sector. Util. Pol. 19 (4), 211-217.

Herrera-Dappe, M., Suárez-Alemán, A., 2016. Competitiveness of South Asia's Container Ports: A Comprehensive Assessment of Performance, Drivers, and Costs. Directions in Development. World Bank, Washington, DC. https://doi.org/10.1596/978-1-46480892-0.

Herrera, S., Pang, G., 2005. Qué tan Eficiente es el Gasto Público en Educación? (How Efficient is Public Spending in Education?). Ensayos Sobre Polit. Econ. 51, 136-201.

International Monetary Fund, IMF, 2015. Making Public Investment More Efficient. IMF Policy Paper, Washington DC (USA).

IMF (International Monetary Fund), 2016. Making Public Investment More Efficient. International Monetary Fund, Washington, DC.

Infralatam, 2018. Economic Infrastructure Investment Data in Latin America and the Caribbean. www.infralatam.info.

Jaimurzina, A., Sánchez, R., 2017. "Governance of Infrastructure for Sustainable Development in Latin America and the Caribbean: an Initial Premise." Economic Commission for Latin America and the Caribbean (ECLAC) FAL Bulletin.

Jolliffe, I.T., Cadima, J., 2016. Principal component analysis: a review and recent developments. Phil. Trans. R. Soc. A 374 (2065).

Kaufmann, D., Kraay, Aart, Mastruzzi, Massimo, 2010. The Worldwide Governance Indicators: Methodology and Analytical Issues." Policy Research Working Paper 5430. World Bank, Washington, DC. http://papers.ssrn.com/sol3/papers.cfm? abstract_id $=1682130$.

Kenny, C., 2009. Measuring corruption in infrastructure: evidence from transition and developing countries. J. Dev. Stud. 45 (3), 314-332.

Llungo-Ortiz, J., 2014. Privatization of Telecommunications in Latin America, an Analysis of its Efficiency.

Murray, S., 2015. The Construction Productivity Paradox. Infrastructure Intelligence.

Oliveira, R.C.D., Tostes, M.E.D.L., 2017. Analysis of the Brazilian energy efficiency program for electricity distribution systems. Energies 10 (9), 1391.

Perrotti, D., Sánchez, R.J., 2011. "La Brecha de Infraestructura en América Latina y el Caribe." (The Infrastructure Gap in Latin America and the Caribbean.) Serie Recursos Naturales e Infraestructura, vol. 153 United Nations, Santiago, Chile.

Pombo, C., Taborda, R., 2006. "Performance and efficiency in Colombia's power distribution system: effects of the 1994 reform. Energy Econ. 28 (3), 339-369.

Serebrisky, T., 2012. Airport Economics in Latin America and the Caribbean: Benchmarking, Regulation, and Pricing. Directions in Development, Infrastructure. World Bank, Washington, DC.

Serebrisky, T., Sarriera, J.M., Suárez-Alemán, A., Araya, G., Briceño-Garmendía, C., Schwartz, J., 2016. Exploring the drivers of port efficiency in Latin America and the Caribbean. Transport Pol. 45, 31-45.

Serebrisky, T., Suárez-Alemán, A., Margot, D., Ramirez, M.C., 2015. Financing Infrastructure in Latin America and the Caribbean: How, How Much and by Whom? Inter-American Development Bank.

Serebrisky, T., Suárez-Alemán, A., Pastor, C., Wohlhueter, A., 2018. Lifting the Veil on Infrastructure Investment Data in Latin America and the Caribbean. Report IDB-TN01380. Inter-American Development Bank, Washington, DC.

Serebrisky, T., Suárez-Alemán, A., Pastor, C., Wohlhueter, A., 2017. Increasing the Efficiency of Public Infrastructure Delivery: Evidence-Based Potential Efficiency Gains in Public Infrastructure Spending in Latin America and the Caribbean. InterAmerican Development Bank.

Sherman, H.D., Zhu, J., 2006. Service Productivity Management: Improving Service Performance Using Data Envelopment Analysis (DEA). Springer Science \& Business Media.

Suárez-Alemán, A., Sarriera, J.M., Serebrisky, T., Trujillo, L., 2016. When it comes to container port efficiency, are all developing regions equal? Transport. Res. Pol. Pract. $86,56-77$.

World Economic Forum, 2018. Global Competitiveness Report.

World Economic Forum, 2016. This Is Why Construction Is So Corrupt.” February 14. 2018. World Bank Open Data. https://data.worldbank.org/.

Wu, J., Chu, J., Zhu, Q., Li, Y., Liang, L., 2016. Determining common weights in data envelopment analysis based on the satisfaction degree. J. Oper. Res. Soc. 67 (12), 1446-1458. 